\title{
Counseling LGBT Military Clients Using the Multicultural and Social Justice Counseling Competencies Framework
}

\author{
Rebekah F. Cole, PhD, LPC, NCC \\ Uniformed Services University of the Health Sciences, Bethesda, Maryland, United States \\ (iD) https://orcid.org/0000-0003-2628-8658
}

Contact: rebekah.cole@usuhs.edu

\begin{abstract}
When working with LGBT service member clients, counselors should use the Multicultural and Social Justice Counseling Competencies as a framework to guide their practice as they navigate the intersection between the military culture and LGBT culture. This framework addresses four domains that are foundational for multicultural and social justice competency: (a) counselor self-awareness, (b) the client worldview, (c) the counseling relationship, and (d) counseling and advocacy interventions. Included in the framework are the following aspirational competencies within each domain: attitudes and beliefs, knowledge, skills, and action. Best practices for culturally competent, social-justice-focused work with LGBT service members within each of these domains are discussed.
\end{abstract}

Keywords: military culture, sexual identity, multicultural and social justice counseling competencies

Date Submitted: March 23, 2021 | Date Published: August 7, 2021

Recommended Citation

Cole, R. (2021). Counseling LGBT military clients using the Multicultural and Social Justice Counseling Competencies Framework. Journal of Social Change, 13(2), 67-79. https://doi.org/10.5590/JOSC.2021.13.2.06

\section{Introduction}

In the U.S. military, $12 \%$ of female service members and $3 \%$ of male service members identify as LGBT (Davis et al., 2016). LGBT service members have been affected by legislation throughout history (Naval Institute Staff, 2018; Sinclair, 2009). The first official policy affecting this population was made by the Department of Defense in 1982, which prohibited anyone identifying as LGBT from serving in the U.S. military. The next monumental legislation involving this population was in 1993, when President Clinton signed the “Don't Ask Don't Tell" legislation, allowing LGBT service members to serve in the military as long as they did not openly discuss or express their sexuality (Georgetown Law Library, 2021). This legislation was repealed by President Obama in 2011, allowing LGBT service members to openly express their sexual orientation (USC, 2018). Later in 2015, the Department of Defense announced that same-sex military spouses would receive military healthcare benefits, a revolutionary advancement for LGBT service members and their families. However, in 2017, President Trump banned all transgender individuals from serving in the military (Naval Institute Staff, 2018). This policy was then reversed by President Biden through an executive order in January 2021, allowing transgender service members to openly serve in the military (Tran, 2021). 


\section{LGBT Service Members' Mental Health}

LGBT service members have demonstrated poorer mental and physical health, are subject to more sexual trauma, experience more of a stigma toward receiving mental health services, and are at a higher risk of suicide compared with heterosexual service members (Blosnich et al., 2015; Johnson et al., 2015; Maltseva et al., 2019; Matarazzo et al., 2014; Mark et al., 2019). Additional mental health risk factors for LGBT service members include high rates of substance abuse, a stigma regarding their sexuality, sexual harassment, and victimization (Meadows et al., 2015; Johnson et al., 2015; Matarazzo et al., 2014).

\section{Military Culture and Collectivism}

To fully understand the experiences of LGBT service members, it is important to take a close look at the military culture, especially its collective nature. The military culture has its own set of customs, rules, expectations, and language that affects a service member's daily life (Meyer, 2015). When joining the military, service members forfeit aspects of their personal identity-i.e., their choice of dress, the right to free speech, the right to a trial by jury-and to follow strict rules and regulations (Burek, 2018). This mission-focused orientation creates a sense of self-sacrifice and a warrior ethos among service members, who commit to collectively carrying out the mission of the military in every aspect of their lives (Meyer, 2015).

\section{The Multicultural and Social Justice Counseling Competencies (MSJCC)}

To help LGBT service members navigate the complex intersection of the military culture and their LGBT culture, counselors should use the Multicultural and Social Justice Counseling Competencies (MSJCC) as a framework to guide their practice (Ratts et al., 2015). The MSJCC provides a comprehensive approach for increasing self-awareness and gaining the knowledge and skills necessary to take action and advocate for this population. Sue et al. (1992) initially developed this framework for culturally competent approaches to working with diverse populations and labeled it MSJCC. Later, in 2015, this framework was revised by The MSJCC Revisions Committee and was endorsed by the Association for Multicultural Counseling and Development Executive Council and American Counseling Association Governing Council (Ratts et al., 2015, 2016). This revised framework includes a new focus on social justice and action and addresses how power, privilege, and oppression influence the counseling relationship between the counselor and client. It describes four domains that are foundational for multicultural and social justice competence: (1) counselor selfawareness, (2) client worldview, (3) counseling relationship, and (4) counseling and advocacy interventions. Each of the first three layers includes the following aspirational competencies: attitudes and beliefs, knowledge, skills, and action. The fourth, the counseling and advocacy intervention layer, uses a multilevel socioecological model to inspire and equip counselors to intentionally and actively engage in social justice advocacy. Overall, in the MSJCC model, counselors are called to recognize their clients' multiple cultural identities as well any intersecting privileged or marginalized statuses between the counselor and the client (Ratts et al., 2016).

In this article, I focus on counselors' work with LGBT service members experiencing a unique intersection between their military and sexual minority identities and how counselors can utilize the MSJCC to effectively work with this population. Due to their sexual minority status, these clients are categorized as marginalized clients. Therefore, it is important for counselors to consider the intersection of their client's identity as a service member, as well as their marginalized sexual identity, as they apply the MSJCC in working with this population (Ratts et al., 2016). While past research has explored culturally competent approaches to working with service members and veterans (Carrola \& Corbin-Burdick, 2015; Cole, 2015; Meyer, 2015; Westphal \& Convoy, 2015), there is a gap in best practices regarding culturally competent work with LGBT service member clients (Goldbach \& Castro, 2016). Therefore, I use the MSJCC as a framework for how professional counselors can demonstrate cultural competence in their attitudes and beliefs, knowledge, and skills when working with LGBT service members. By using this framework as a guide, counselors can develop greater selfawareness, gain more in-depth understanding of the LGBT service member's worldview, and take action to advocate for and with this population from a systemic perspective. 


\section{Counselor Self-Awareness}

When beginning their work with LGBT service members, counselors must focus on the first MSJCC developmental domain, self-awareness, which involves taking action to become more aware of and knowledgeable about one's attitudes and beliefs, ultimately obtaining the knowledge and skills to effectively work with LGBT service members in a culturally competent manner (Ratts et al., 2015).

\section{Attitudes and Beliefs}

Multicultural and social-justice-competent counselors believe that their own culture, including their civilian culture, affects their attitudes, values, and biases as a professional counselor working with LGBT service members (Ratts et al., 2015). Counselors should likewise determine their position as a privileged or marginalized member of society and how this position affects their work with marginalized LBGT service member clients (Ratts et al., 2016). A self-exploration regarding one's position in society (i.e., marginalized or privileged) and personal beliefs might be done in individual or group supervision or their own counseling sessions. When engaging in this self-reflection, counselors should explore their limits of cultural competence as a civilian who has not experienced the military lifestyle and, possibly, as a privileged member of society if they do not identify as LGBT.

Finally, according to the MSJCC, counselors should recognize and explore any source of discomfort in working with LGBT service members as a result of past perceptions or encounters with either the LGBT community and/or military culture (Ratts et al., 2015). Questions such as "what have my perceptions of LGBT service members been in the past?" and "what is the root of my discomfort?" are key to ask and process throughout the counseling process to screen for any discriminatory thoughts or feelings that may cause harm to the client.

\section{Knowledge}

When using the MSJCC as a framework for their work with LGBT service members, counselors become more self-aware about their own civilian cultural worldview and sexual identity and how this worldview and identity affect their interactions with LGBT service members in the counseling relationship (Ratts et al., 2015). The counselor should also consider how their unfamiliarity with the military lifestyle and culture as well as the LGBT culture and lifestyle, including the language and terminology used during the counseling session, might become apparent to the client and how this will affect the client's trust in the counseling process. Finally, to become more prepared to work with this population, counselors should engage in research regarding the nature of military culture and LGBT culture, the intersection of both, and the many challenges that LGBT service members have faced throughout the course of military history to understand the roots and context of their presenting problems and to better understand the nature of the client's struggles.

\section{Skills}

As described in the MSJCC, culturally skilled counselors working with LGBT service members seek out educational, consultative, and training experiences so that they can develop the necessary skills to help this population (Ratts et al., 2015). If counselors feel like they are not able to develop these specialized skills, they should refer LGBT service member clients to providers who have the specialized skills to work with that population (Ratts et al., 2015). Counselors should create a comprehensive list of these specialized providers in the community, in preparation if a referral is needed.

Overall, multicultural and social-justice-competent counselors actively and continually seek to understand themselves as cultural beings and actively look to maintain a culturally competent professional identity through supervision, continued education, and practice (Ratts et al., 2015). Multicultural and social-justice competent counselors working with LGBT service members must be committed to constantly growing in their cultural competence throughout their professional careers as the needs of this population evolve over time. 


\section{Action}

According to the MSJCC, counselors must take action to learn about their assumptions regarding this population and to increase their comfort level in counseling LGBT service members (Ratts et al., 2015). Questions for self-reflection (or with a counselor, a college, or with a supervisor) might include: "What initial reaction do I have when thinking about LGBT service members?" "What do I know about the history of LGBT service in the military?" "What are my individual assumptions about the military, about the LGBT population?" "How do these assumptions impact my work as a professional counselor with this population?" In addition to exploring answers to these questions, culturally social-justice-competent counselors should assess how much they know about the history of LGBT in the military, the challenges this population faces, and best practices in the professional literature for addressing these challenges. They should then seek out professional development for any knowledge areas in which they are lacking to better prepare themselves to work with this population (Ratts et al., 2015, 2016).

In addition to this active self-reflection, counselors should immerse themselves as much as possible into both the LGBT and military communities. They should interact with LGBT service members as much as possible and analyze and evaluate their comfort level in working with this population (Ratts et al., 2015). Opportunities for this immersion may come in the form of participating in activities on base/post and volunteering with organizations that serve active-duty members, veterans, and military families (Cole, 2014). Counselors should then process these immersion experiences with their own counselor or supervisor, asking questions such as "what was my reaction to integrating into this community?" or "what was it like for me to interact with LGBT service members?”

Finally, counselors should consider how an LGBT service member's communication style is influenced by their marginalized status (Ratts et al., 2015). For example, the client may be hesitant to reveal and communicate their true self in their counseling sessions because it has been oppressed by the military for so long. The counselor, therefore, will need to build trust in the counseling relationship, creating a safe space for the client to reveal and share themselves in an authentic way (Okun \& Kantrowitz, 2015), something they may not feel free to do in their daily life as a part of the military community.

\section{LGBT Service Members' Worldview}

In addition to actively exploring their own worldview and becoming more self-aware, it is important that counselors have a full understanding of LGBT service members' worldview, the next developmental domain in the MSJCC framework. They must be fully aware of their own attitudes and beliefs about it, develop an indepth understanding of it, demonstrate skills applicable to it, and take action to continually learn more about it (Ratts et al., 2015).

\section{Attitudes and Beliefs}

First, to understand their attitudes and beliefs about LGBT service members' worldviews, culturally aware counselors engage in continued self-exploration (Ratts et al., 2015), asking questions such as "what are my personal and political beliefs about LGBT service members?" and "how might my perceptions of LGBT service members' reality differ from their true reality?” The answers to these questions might be explored through supervision, consultation with peers, and consistent reflective journaling to gain a full and robust awareness of how the counselor's perceptions of the client's worldview may be affected by their own worldview (Farmer \& Disque, 2013; Woodbridge \& O’Beirne, 2017).

\section{Knowledge}

Culturally knowledgeable counselors should be well-versed in how their life experiences, cultural heritage, and historical background affect their professional identity and their work with LGBT service members (Ratts et al., 2015). For example, a counselor might ask, "what is my extended family's view of the LGBT community? 
of the military community? of LGBT service members?" and "how will my family's beliefs affect my interactions with LGBT service members?" Overall, this level of understanding comes through deep and honest reflection and examination of one's values and beliefs and how these values and beliefs relate to both the military population, the LGBT population, and the intersection of these cultures resulting in the marginalized LGBT service member population.

In addition to this in-depth self-analysis, when deciding on which counseling approach to use with LGBT clients, counselors are called upon to understand how the intersection of the military culture and LGBT identity affects the client's personality, career path, and mental health (Ratts et al., 2015). Open-ended questions such as "what is it like for you to serve as an LGBT individual in the military?" or "how would your life be different if you weren't in the military?" may help to understand how the intersection of the military and sexual orientation have impacted the client's overall mental health and functioning.

Finally, multicultural and social-justice-competent counselors should be knowledgeable about sociopolitical influences that affect the worldviews of LGBT service members (Ratts et al., 2015). Military service members are governed by the military's strict rules and regulations (Cole, 2014). Their ability to abide by these rules and regulations impacts their career and their family's financial situation. Thus, the pressure to behave and conform (and, perhaps, to hide their true identity) is immense for them. Understanding this pressure of LGBT service members to hide their true identity is key to demonstrating genuine empathy for this population.

\section{Skills}

To use best practices and counseling approaches for working with LGBT service members, counselors are called upon to familiarize themselves with relevant research and the latest findings regarding mental health and mental disorders that affect this population (Ratts et al., 2015). In addition, counselors should actively seek out educational experiences that enrich their knowledge, understanding, and cross-cultural skills for their work with LGBT service members (Ratts et al., 2015, 2016). These experiences could be found at local, state, and national conferences or in the form of professional development webinars, provided by professional organizations, that are aimed at counseling LGBT service members and their families.

Finally, according to the MSJCC framework, counselors should become involved with the military community as much as possible so that they can become more comfortable and familiar with the lived experiences of LGBT service members and are better able to understand their worldview (Ratts et al., 2015). Many volunteer opportunities exist on military bases through organizations like the USO, where volunteers can directly work with active-duty service members and their families and become more confident and knowledgeable about navigating the military culture. Spending time and interacting with this community as much as possible will help the counselor better understand the culture and the worldview of the LGBT service member client.

\section{Action}

Action-oriented culturally competent counselors should seek out opportunities to talk about the experiences of LGBT service members throughout history (Ratts et al., 2015). These conversations may happen with colleagues, in meetings with military leadership, politicians, and LGBT service members themselves. In addition, counselors should actively seek out opportunities within the military community where they can support and affirm the intersection between the LGBT culture and military culture (Ratts et al., 2015). For example, the month of June is designated as Pride Month in the military (Washington Headquarters Service, 2020). During June, ceremonies are held on military bases highlighting the importance of LGBT service members to the mission of the military. Counselors might attend these ceremonies as a volunteer, public speaker, or advisor to the planning committee so as to meet LGBT service members and support them as they are honored for their contributions to the military (Cronk, 2019).

Finally, counselors should regularly assess their limitations and strengths in working with LGBT service members (Ratts et al., 2015). Counselors might include questions for reflection: "How have I grown in my knowledge of the challenges that LGBT service members face?" "In what ways can I become more comfortable 
and competent in working with this population?" Any limitations should be addressed through continuous professional development and/or consultation with colleagues who are experienced advocates for this population. Overall, throughout their careers, counselors should set measurable benchmarks for themselves in growing more comfortable and confident in working with LGBT service members and self-assess their progress in meeting these benchmarks.

\section{Counseling Relationship}

In addition to focusing on how to increase their self-awareness and better understand LGBT service members' worldviews, counselors should understand how both the counselor's and the client's privileged and marginalized statuses affect the counseling process and relationship (Ratts et al., 2015, 2016). This understanding comes through actively learning about and understanding the nature of privileged versus marginalized statuses in society and in the military and how client and counselor worldviews affect the counseling relationship (Ratts et al., 2016). In addition, counselors develop and fine tune their basic helping skills to have productive and meaningful conversations with LGBT service member clients about what it means to be marginalized and how this marginalization may affect the counseling relationship (Ratts et al., 2015).

\section{Attitudes and Beliefs}

Multicultural and social-justice-competent counselors understand that a counselor's attitudes and beliefs heavily influence the counseling relationship (Ratts et al., 2015). Multicultural and social-justice-competent counselors respect LGBT service members' military culture and values (i.e., honor, courage, commitment to the U.S. military) because they believe that these values affect their worldview, psychosocial functioning, and expressions of distress (Krueger, 2000). It is important to understand and respect the values they hold as a service member and their intersecting sexual identity, and counselors need to understand the ways in which this intersection proves challenging (Ratts et al., 2016).

Culturally skilled counselors respect helping networks and sources of support within the military community (Ratts et al., 2015), such as on-base or on-post military mental health resources and chaplains. Counselors must become familiar with on-base or on-post mental health resources and coordinate with these resources to provide support for LGBT service members. Counselors are likewise called to value bilingualism as a part of their cultural competence, recognizing the unique nature of the military language and being willing to learn and use this language in their interactions with LGBT service members (Ratts et al., 2015). Understanding and using this language can build rapport and trust with the client throughout the counseling process (Canady, 2018).

\section{Knowledge}

Culturally knowledgeable counselors understand institutional barriers that prevent LGBT service members from seeking or receiving counseling (Ratts et al., 2015). These barriers include a stigma in military culture surrounding mental health and seeking mental health services or past negative experiences with military healthcare providers who are not accepting or supportive of LGBT service members (McNamara et al., 2021). Other barriers may be the difficulty of accessing military and/or civilian mental health services where they are stationed that are familiar and comfortable working with the LGBT population. In addition, multicultural and social-justice-competent counselors have a thorough knowledge of the military community and its resources, or lack thereof, in supporting LGBT service members, including on-base or on-post counseling, chaplains, and Military One Source, where service members and their families can access comprehensive information regarding mental health and wellness (Ratts et al., 2015). 


\section{Skills}

Counselors working with LGBT service members are called on to use a variety of verbal and nonverbal helping responses as they recognize the diverse and unique needs of this population (Ratts et al., 2015). Counselors should understand that not all LGBT clients will need the same course of treatment, as each is a unique individual with diverse experiences and backgrounds (Okun \& Kantrowitz, 2015). Counselors should use their supervisors to determine which counseling approach may work best with each client and evaluate the effectiveness of this approach throughout the counseling process.

Multicultural and social-justice-competent counselors seek consultation with knowledgeable cultural experts within the military community, such as chaplains and on-base/on-post counselors, to best understand the military culture and the mental health needs of LGBT service members within this culture (Ratts et al., 2015). Culturally skilled counselors are likewise committed to learning the military language so that they can fluidly use it in their counseling sessions with LGBT service members (Ratts et al., 2015). This language can be practiced through volunteer work or attending community-wide events open to the public within the military community to gain fluency.

Multicultural and social-justice-competent counselors additionally evaluate assessment instruments normally geared toward heterosexual clients to determine if they are biased toward LGBT service member clients in any way (Moe et al., 2015; Ratts et al., 2015). For example, counselors must consider "is the language in the assessment inclusive?" or "are the results being interpreted from an inclusive perspective?" or "does the client feel comfortable in providing authentic responses?" (Prince, 1997). Ensuring this comfort level is key in using assessment instruments with LGBT service members, given reluctance they may feel in presenting their authentic selves (McNamara et al., 2020).

Finally, culturally skilled counselors educate their LGBT military clients about the counseling process and carefully explain topics, such as confidentiality, that are important to the military lifestyle (Ratts et al., 2015). Because of the stigma associated with receiving mental health services that exists in the military culture (Sharp et al., 2015), it is important to assure the service member client that the issues discussed in the session will remain confidential and will not be disclosed to military superiors for any reason.

\section{Action}

Multicultural and social-justice-competent counselors initiate conversations with LGBT service member clients to understand how the client-counselor relationship is influenced by worldviews, values, beliefs, and biases (Ratts et al., 2015). The counselor should seek the expertise of the client in these conversations, creating a safe environment for honesty in reflection from a person-centered approach (Seligman \& Reichenberg, 2013). Multicultural and social-justice-competent counselors likewise partner with clients to decide what type of advocacy is needed both in the military and in the civilian community (Ratts et al., 2015). Counselors involve and empower clients in this conversation and treat them as the experts on their own experiences and potential (Seligman \& Reichenberg, 2013). Finally, multicultural and social-justicecompetent counselors use cross-communication skills to connect with clients (Ratts et al., 2015), including active-listening, open-ended questioning, and reflection of feelings. These skills will allow the client to feel truly heard and will build trust within the counseling relationship (Okun \& Kantrowitz, 2014).

\section{Counseling and Advocacy Interventions}

The fourth and final MSJCC domain focuses on how counselors can advocate for their LGBT service member clients and can empower them to advocate for themselves from both an individual (intrapersonal and interpersonal) and systemic (institutional, community) perspective (Ratts et al., 2015). 


\section{Intrapersonal}

Multicultural and social-justice-competent counselors help LGBT service member clients develop a critical consciousness by understanding their challenges in the context of an oppressive society or how they are affected by the military's past and current viewpoint on their sexual orientation (Ratts et al., 2015). Counselors are called upon to help LGBT service member clients build confidence and learn how to selfadvocate both within the military community and in civilian society (Ratts et al., 2015). Clients need to be supported as they go against the collective norm in the military, which they have been trained to conform to as a part of the military culture since the first day of their careers.

\section{Interpersonal}

Next, multicultural and social-justice-competent counselors help LGBT service member clients analyze the relationships they have with others in the military as well as in their personal lives that may be impacted by their marginalized status (Ratts et al., 2015). LGBT service members should understand the impact of historical legislation on LGBT service members in the military and how this legislation may affect their interactions with others in their work and daily life (Ratts et al., 2015). To provide support for LGBT service members in engaging in this reflection, multicultural and social-justice-competent counselors create support groups for LGBT service members to discuss the challenges they have faced and the coping strategies they have found to be helpful. In these groups, counselors can help LGBT service members articulate their intersecting cultural identities and discuss how they can openly and authentically describe their experiences to their family, friends, and co-workers.

In addition to these support groups for LGBT service members, counselors might facilitate support groups for the family members of LGBT service members to provide them with the education, tools, and resources for navigating the military lifestyle and their marginalized status. Multicultural and social-justice-competent counselors should also connect LGBT service members with mentors in the military and in the community, such as active duty or veteran LGBT service members, who can share their own experiences and help support them in overcoming the challenges they face within the military culture.

\section{Institutional}

In addition to an interpersonal focus, multicultural and social-justice-competent counselors determine which social institutions can help LGBT service members overcome the challenges they are facing (Ratts et al., 2015). For example, the Fleet and Family counseling centers on military bases, military-friendly agencies within the civilian community, or local houses of worship may serve as sources of support and referrals for the LGBT service member community. In addition to making client referrals to these institutions, multicultural and social-justice-competent counselors join with social institutions to address injustice (Ratts et al., 2015). These partnerships may include joining with military leadership who are committed to advocating for LGBT service members. Counselors should likewise collaborate with Public Affairs Offices on military bases to promote LGBT equality on military social media pages and on local and national media outlets, ultimately working to shape the public's opinion and viewpoint of the contributions this population makes to the military community.

As trained cultural experts (Pieterse, 2009), counselors can offer insights to military leadership on the mental health needs of LGBT service members and ways in which the military community can support this traditionally marginalized population. In addition, counselors should work with military leadership in creating inclusive environments in the workplace where LGBT service members will be safe and celebrated. One step that military leadership might take, for example, is creating a diversity council in each unit that will plan practical strategies for creating a culture of acceptance and inclusion within the military culture. Counselors might look to other industries that have created inclusive working environments for additional strategies that would prove effective in the military work environment as well. Overall, counselors should collaborate with military leadership to discover ways to mitigate the challenges faced by LGBT service 
members. By skillfully facilitating these difficult conversations and challenging military personnel to face and address the past, an action plan for change can be made.

Finally, multicultural and social-justice-competent counselors should offer training for military mental health providers regarding the healthcare needs of the LGBT population. This type of training has been found to be well received and effective in the past by military medical personnel (Shrader et al., 2017) and could be designed or adjusted to educate on-base or on-post mental health counselors. Counselors should also partner with school counselors in Department of Defense schools on military bases to offer professional development related to working with LGBT service members and their families.

\section{Community}

Multicultural and social-justice-competent counselors discuss and explore the experiences of LGBT service members (Ratts et al., 2015). Counselors should also conduct research (i.e., focus groups, surveys) to investigate how much military norms, values, and regulations, both past and present, influence LGBT service members and the marginalization they experience in the military (Ratts et al., 2015). This research could be done with LGBT service member participants, heterosexual service members, and military leadership participants to analyze and explore each of their perspectives. In addition, counselors might conduct needs assessments with civilian and military providers working with LGBT clients to understand their experiences and training needs. Then, an action plan can be drafted and implemented in collaboration with these stakeholders to fill any training gaps (Zajac \& Godshall, 2020).

Overall, multicultural and social-justice-competent counselors should empower their LGBT service member clients to help shape the military's norms, values, and regulations to normalize diversity in sexual orientation in military culture (Ratts et al., 2015). For example, the counselor might help the LGBT service member client overcome fears of revealing their sexual identity to their peers or brainstorm ways in which the client can systemically challenge the oppressive culture of the workplace so that LGBT service members are no longer marginalized members of the military community.

\section{Future Research}

Future qualitative research should explore the experiences of LGBT service members to understand the true nature of their worldviews and the intersection between their sexual identity and position in the military. Qualitative research might likewise explore the experiences of both military and civilian counselors working with this population to determine clinical strengths as well as in what areas they might need additional professional development to best help this population overcome the challenges that they face as a marginalized population within the military culture.

Future quantitative research might survey LGBT service members to determine how the effects of recent oppressive legislation during the Trump administration have affected their physical and mental health. These results would be useful in advocating for additional services for this population within the military as well as creating an awareness of the effects of such policies on their mental health. Future quantitative research might likewise survey the families of LGBT service members to understand their experiences as marginalized military families and to determine what supportive resources may be needed for them both from military and civilian mental health providers.

Finally, both quantitative and qualitative research should investigate the effectiveness of using the MSJCC as a framework for counseling LGBT service members. Then, this evidence-based framework can be widely integrated into professional development opportunities for civilian and military mental health providers and could be used as a model framework in counselor education programs to train counselors to effectively help LGBT service members and to actively advocate for their needs from both an individual and systemic perspective. 


\section{Conclusion}

Because of the complex and unique nature of the intersection between the LGBT sexual identity and military culture, it is important for counselors to approach their work with this population in a culturally competent manner. The MSJCC provides a guiding framework for gaining the knowledge, skills, and awareness to work with LGBT service members as well as an action plan for advocating for just treatment of this population within the military culture. Counselors cannot be satisfied with counseling LGBT service members from the comfort of their office, but must take on a systemic, action-oriented, advocacy perspective to effectively meet the needs of this population. 


\section{References}

Ayoub, P. M. (2015). Contested norms in new-adopter states: International determinants of LGBT rights legislation. European Journal of International Relations, 21(2), 293-322. https://doi.org/10.1177/1354066114543335

Blosnich, J. R., Gordon, A. J., \& Fine, M. J. (2015). Associations of sexual and gender minority status with health indicators, health risk factors, and social stressors in a national sample of young adults with military experience. Annals of Epidemiology, 25(9), 661-667.

https://doi.org/10.1016/j.annepidem.2015.06.001

Burek, G. (2018). Military culture: Working with veterans. The American Journal of Psychiatry, 13(9), 3-5. https://doi.org/10.1176/appi.ajp-rj.2018.130902

Canady, V. A. (2018). More bilingual mental health counselors needed to serve as language brokers. Mental Health Weekly, 28(40), 1-8. https://doi.org/10.1002/mhw.31636

Carrola, P., \& Corbin-Burdick, M. F. (2015). Counseling military veterans: Advocating for culturally competent and holistic interventions. Journal of Mental Health Counseling, 37(1), 1-14. https://doi.org/10.17744/mehc.37.1.v74514163rv73274

Cronk, T. M. (2019, June 13). Pentagon celebrates diversity at LGBT Pride Month observance. https://www.defense.gov/Explore/News/Article/Article/1874601/pentagon-celebrates-diversity-atlgbt-pride-month-observance/

Cole, R. F. (2014). Understanding military culture: A guide for professional school counselors. The Professional Counselor, 4(5), 497-504. https://doi.org/10.15241/rfc.4.5.497

Davis, L., Grifka, A., Williams, K., \& Coffey, M. (Eds.). (2016). 2016 Workplace and gender relations survey of active duty members: Overview report. U.S. Department of Defense, Office of People Analytics. http://www.sapr.mil/public/docs/reports/FY16_Annual/Annex_1_2016_WGRA_Report.pdf

Farmer, L. B., \& Disque, G. (2013). Harmonic inquiry: A supervision technique for developing selvesawareness. Vistas Online. https://www.counseling.org/docs/default-source/vistas/harmonicinquiry.pdf?sfvrsn $=$ de2c $78 \_10$

Flores, R. (2019). Social acceptance of LGBT people in 174 countries: 1981 to 2017. https://escholarship.org/content/uc/item/5qs218xd

Georgetown Law Library. (2021). A brief history of civil rights in the United States. https://guides.ll.georgetown.edu/c.php?g=592919\&p=4182200

Goldbach, J. T., \& Castro, C. A. (2016). Lesbian, gay, bisexual, and transgender (LGBT) service members: Life after don't ask, don't tell. Current Psychiatry Reports, 18(6), 1-7. https://doi.org/10.1007/s11920016-0695-0

Gurung, S., Ventuneac, A., Rendina, H. J., Savarese, E., Grov, C., \& Parsons, J. T. (2018). Prevalence of military sexual trauma and sexual orientation discrimination among lesbian, gay, bisexual, and transgender military personnel: A descriptive study. Sexuality Research and Social Policy, 15(1), 7482. https://doi.org/10.1007/s13178-017-0311-z

Johnson, W. B., Rosenstein, J. E., Buhrke, R. A., \& Haldeman, D. C. (2015). After “Don’t ask don’t tell”: Competent care of lesbian, gay and bisexual military personnel during the DoD policy transition. Professional Psychology: Research and Practice, 46(2), 107-115. https://doi.org/10.1037/a0033051

Krueger, G. P. (2000). Military culture. In A. E. Kadzin (Ed.). Encyclopedia of psychology (Vol. 5, pp. 252259). American Psychological Association. https://doi.org/10.1037/10520-111

Maltseva, T., Olenick, M., Flowers, M., \& Diez-Sampedro, A. (2019). Understanding suicidal risk of LGBT veterans: A call for action. Journal of Trauma Treatment, 8(1). 
Mark, K. M., McNamara, K. A., Gribble, R., Rhead, R., Sharp, M., Stevelink, S. A. M., Schwartz, A., Castro, C., \& Fear, N. T. (2019). The health and well-being of LGBT serving and ex-serving personnel: A narrative review. International Review of Psychiatry, 31(1), 75-94. https://doi.org/10.1080/09540261.2019.1575190

Matarazzo, B. B., Barnes, S. M., Pease, J. L., Russell, L. M., Hanson, J. E., Soberay, K. A., \& Gutierrez, P. M. (2014). Suicide risk among lesbian, gay, bisexual, and transgender military personnel and veterans: What does the literature tell us? Suicide \& Life-Threatening Behavior, 44(2), 200-217. https://doi.org/10.1111/sltb.12073

McNamara, K. A., Lucas, C. L., Goldbach, J. T., Holloway, I. W., \& Castro, C. A. (2021). "You don't want to be a candidate for punishment": A qualitative analysis of LGBT service member "outness". Sexuality Research and Social Policy, 18(1), 144-159. https://doi.org/10.1007/s13178-020-00445-x

Meadows, S. O., Engel, C. C., Collins, R. L., Beckman, R. L., Cefalu, M., Hawes-Dawson, J., Waymouth, M., Kress, A. M., Sontag-Padilla, L., Ramchand, R., \& Williams, K. M. (2015). 2015 Department of Defense Health Related Behaviors survey (HRBS). RAND.https://doi.org/10.7249/RR1695

Meyer, E. G. (2015). The importance of understanding military culture. Academic Psychiatry 39, 416-418. https://doi.org/10.1007/s40596-015-0285-1

Moe, J. L., Finnerty, P., Sparkman, N., \& Yates, C. (2015). Initial assessment and screening with LGBTQ clients: A critical perspective. Journal of LGBT Issues in Counseling, 9(1), 36-56. https://doi.org/10.1080/15538605.2014.997332

Naval Institute Staff. (2018, March 26). Key dates in the U.S. military LGBT policy. Naval History Blog. https://www.navalhistory.org/2018/03/26/key-dates-in-u-s-military-lgbt-policy

Okun, B. F., \& Kantrowitz, R. E. (2015). Effective helping: Interviewing and counseling techniques (8th ed.). Cengage.

Pieterse, A. L., Evans, S. A., Risner-Butner, A., Collins, N. M., \& Mason, L. B. (2009). Multicultural competence and social justice training in counseling psychology and counselor education: A review and analysis of a sample of multicultural course syllabi. The Counseling Psychologist, 37(1), 93-115. https://doi.org/10.1177/0011000008319986

Prince, J. P. (1997). Assessment bias affecting lesbian, gay male and bisexual individuals. Measurement and Evaluation in Counseling and Development, 30(2), 82-87.

Ratts, M., Singh, A. A., Nassar-McMillan, S., Butler, S. K., \& McCullough, J. R. (2015). Multicultural and Social Justice Counseling Competencies. https://www.counseling.org/doc/defaultsource/competencies/multcultural-and-social-justice-competencies.pdf

Ratts, M. J., Singh, A. A., Nassar-McMillan, S., Butler, S. K., \& McCullough, J. R. (2016). Multicultural and social justice counseling competences: Guidelines for the counseling profession. Journal of Multicultural Counseling and Development, 44(1), 28-48. https://doi.org/10.1002/jmcd.12035

Schuyler, A. C., Klemmer, C., Mamey, M. R., Schrager, S. M., Goldbach, J. T., Holloway, I. W., \& Castro, C. A. (2020). Experiences of sexual harassment, stalking, and sexual assault during military service among LGBT and non-LGBT service members. Journal of Traumatic Stress, 33(3), 257-266. https://doi.org/10.1002/jts.22506

Seligman L. W., \& Reichenberg, L. W. (2014). Theories of counseling and psychotherapy: Systems, strategies, and skills. (4th ed.). Pearson.

Sharp, M.-L., Fear, N. T., Rona, R. J., Wessely, S., Grenberg, N., Jones, J., \& Goodwin, L. (2015). Stigma as a barrier to seeking health care among military personnel with mental health problems. Epidemiologic Reviews, 37(1), 144-162. https://doi.org/10.1093/epirev/mxu012

Shrader, A., Casero, K., Casper, B., Kelley, M., Lewis, L., \& Calohan, J. (2017). Military lesbian, gay, bisexual, and transgender (LGBT) awareness training for health care providers within the military health 
system. Journal of the American Psychiatric Nurses Association, 23(6), 385-392. https://doi.org/10.1177/1078390317711768

Sinclair, G. D. (2009). Homosexuality and the military: A review of the literature, Journal of Homosexuality, 56(6), 701-718. https://doi.org/10.1080/00918360903054137

Soeters, J. (2018). Organizational cultures in the military. In G. Caforio \& M. Nuciari (Eds.). Handbook of the Sociology of the Military (pp. 251-272). Springer. https://doi.org/10.1007/978-3-319-71602-2 13

Sue, D. W., Arredondo, P., \& McDavis, R. J. (1992). Multicultural counseling competencies and standards: A call to the profession. Journal of Multicultural Counseling and Development, 2O(2), 64-88. https://doi.org/10.1002/j.2161-1912.1992.tbo0563.x

Tran, V. (2021, January 25). Human rights campaign on Biden's reversal of the ban on transgender military service. [Press release]. https://www.hrc.org/press-releases/human-rights-campaign-on-bidensreversal-of-the-ban-on-transgender-military-service

University of Southern California (USC). (2018). A brief history of LGBT military policy and improving acceptance, integration and health among LGBT service members. https://dworakpeck.usc.edu/news/brief-history-of-lgbt-military-policy-and-improving-acceptanceintegration-and-health-among

Westphal, R. J., \& Convoy, S. P. (2015). Military culture implications for mental health and nursing care. The Online Journal of Issues in Nursing, 2O(1). https://pubmed.ncbi.nlm.nih.gov/26824262

Woodbridge, L., \& O’Beirne, B.R. (2017). Counseling students perceptions of journaling as a tool for developing reflective thinking. The Journal of Counselor Preparation and Supervision,9(2).

Worthen, M. G. F., Lingiardi, V., \& Caristo, C. (2017). The roles of politics, feminism, and religion in attitudes toward LGBT individuals: A cross-cultural study of college students in the USA, Italy, and Spain. Sexuality Research and Social Policy, 14, 241-258. https://doi.org/10.1007/s13178-016-0244-y

Zajac, C., \& Godshall, K. C. (2020). Empowerment through accessibility: Community needs assessment data for LGBTQ communities. Social Work in Public Health, 35(6), 483-493. https://doi.org/10.1080/19371918.2020.1798322 manuscripts focusing on interdisciplinary research in social change that improves the human condition and moves people, groups, organizations, cultures, and society toward a more positive future. 